La relación entre el habitar-ethos y la ética. Antropología educativa.

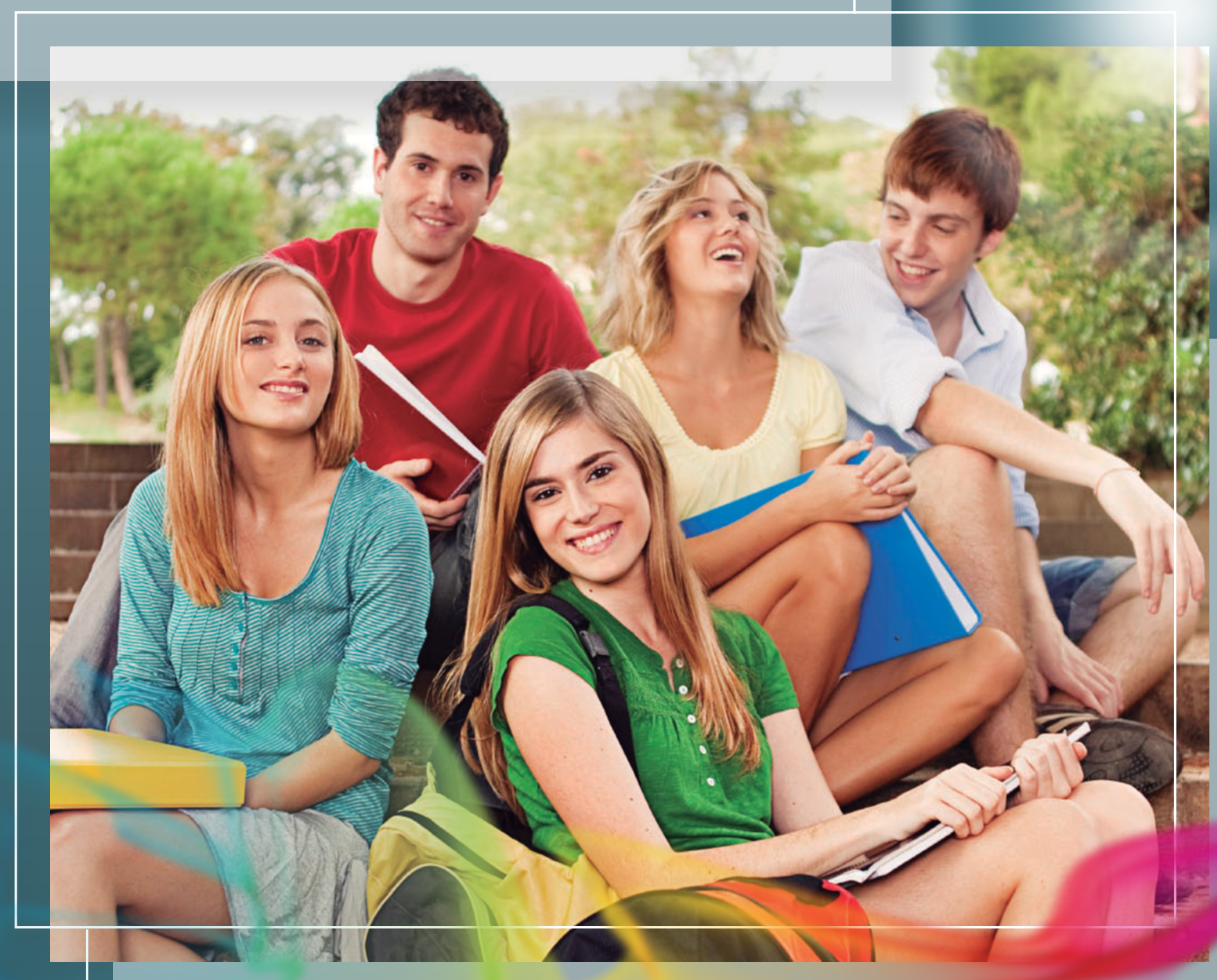




\title{
La relación entre el habitar-ethos y la ética. Antropología educativa ${ }^{1}$ \\ The relationship between live-ethos and ethics. Educational anthropology.
}

\author{
Saúl Ernesto García Serrano ${ }^{2}$ \\ Universitaria de Investigación y Desarrollo (UDI) - Bucaramanga, Colombia.
}

Artículo recibido en octubre de 2015; artículo aceptado en noviembre de 2015.

Citación del artículo: García, S. (2015). La relación entre el habitar-ethos y la ética. Antropología educativa. I+D Revista de Investigaciones, 6(2), 6-18.

\section{Resumen}

Llevar a cabo un proyecto de vida, dejar huella en la humanidad y transitar el camino hacia la madurez y la búsqueda de la felicidad, dependen de la forma como cada persona habita en su propio ser y lo orienta.

El tema del presente artículo nos lleva a reflexionar y relacionar los vocablos habitar y ética, términos íntimamente relacionados en los orígenes del vocablo ethos, comprendido en cuanto forma de residir, morar, costumbres habituales, corazón e interioridad, carácter.

La forma de habitar es una revelación cargada de fuerza y la formación en la universidad contribuye, mediante una antropología educativa, a generar un modo de existir que provoque. Por eso ¿qué estilo de vida se forma en las instituciones educativas? ¿la vida privada es también vida pública? ¿es posible educar para formar la interioridad?

Palabras clave: ethos, persona, formación universitaria, humanismo, educación, antropología educativa.

\section{Abstract}

Carrying out a life and a trace in humanity, make the road to maturity and the pursuit of happiness; it depends on how each person lives in their own self and guides.

\footnotetext{
${ }^{1}$ Artículo de reflexión y orientación teórica con enfoque cualitativo, resultado de una reflexión constante de la labor docente en procesos de formación en la educación superior, Fecha de inicio: agosto 4, 2015, fecha de finalización: 5 de noviembre del 2015.

${ }^{2}$ Licenciado en Filosofía y Ciencias Religiosas, Universidad Santo Tomás. Especialista en Docencia Universitaria, Universidad Santo Tomás. Especialista en Orientación y educación sexual, Universidad Manuela Beltrán. Magíster en Bioética, Pontificia Universidad Lateranense-Roma. Magíster en Ciencias del Matrimonio y la Familia, Pontificia Universidad Lateranense-Roma. Candidato a PhD. en Curriculum, Profesorado, Instituciones educativas, Universidad de Granada-España. Docente-investigador del grupo: FIELDS de la universitaria de Investigación y Desarrollo (UDI) Bucaramanga(Colombia). Calle9 No.23-55.PBX: 6352525.Correo electrónico: saulerga@hotmail.com.
} 
The subject of this article leads us to think and relate the words: ethics and live; terms closely related to the origins of the word ethos, understood as a form of live, common customs, heart and interiority, nature.

The way of living is a revelation full of strength, and training in the university contributes through an educational anthropology to create a way of living that causes reflexing, that is the reason that motivates the question: What lifestyle are shared in educational institutions?, The private life it is also pubic life $?$, is it possible to form the inner educate?

Keywords: ethos, person, university education, humanism, education, educational anthropology.

\section{Introducción}

La educación superior genera un espacio de convivencia para formar personas, ciudadanos y profesionales mediante la relación del corpus docente, políticas de bienestar y la comunidad de estudiantes.

Aprender a saber habitar consigo mismo y con los demás es una competencia para la vida (García, 2015), pues implica suscitar en las instituciones espacios para generar preguntas y respuestas centradas en el movimiento centrípeto de mirar, revisar la manera como se vive, convirtiéndose esta acción en una gran ayuda complementaria al tema de la educación ética porque se favorece, en medio del 'acelere' de la vida, el aprender a contemplar, el saber tomar distancia del mundo instintivo, así como la aspiración y la asimilación de valores como la autenticidad y la coherencia entre vida privada y vida pública.

Por tanto, un aspecto que me parece conveniente y necesario fortalecer en la universidad durante el tiempo en que los estudiantes asimilan sus procesos formativos, es generar la pedagogía de la introspección, la meditación, actitudes ya sugeridas por Francesc Torralba (2010) en su propuesta de favorecer el cultivo de la inteligencia espiritual.

La formación universitaria debe entonces contribuir, de acuerdo con el citado autor a: "La práctica asidua de la soledad, el gusto por el silencio, la contemplación, el ejercicio de filosofar, lo espiritual en el arte, el diálogo socrático, la experiencia de la fragilidad, el deleite musical, la práctica de la meditación y el ejercicio de la solidaridad", de modo que por medio de políticas pedagógicas y de bienestar, así como de la interacción del corpus de la comunidad académica y de los estudiantes, se provoque el reto de la pregunta permanente: ¿depende de cómo se orienta la existencia, dan más ganas de vivir?, ¿es posible educar para abrir nuestra 'casa', de modo que no avergüence el darla a conocer?, ¿hay lugares de nuestro hábitat que merecen ocultarse pues la luz de la verdad no logra aclararlos?, ¿es verdad el apotegma latino: "Corruptio optimi pessima" (la corrupción de lo mejor resulta peor)? (Corchuelo, 2014). 


\section{Ethos, ética: habitar en sí}

"No se conoce a un ser humano hasta que no se penetra en su vida espiritual, hasta que no nos da permiso para acceder a este territorio" (Francesc Torralba).

Siguiendo un análisis realizado por la filósofa mexicana Paulina Rivero, la palabra griega ethos ha tenido su comprensión en momentos históricos de la cultura griega, análisis que convergen hacia un punto común.

El primero, de influjo en la época homérica, es relacionar dicha voz como guarida de refugio (referido a animales) o hábitat humano. Por esta línea, De Finance (1989), ve el vocablo y su significación con casa relacionada como la morada o residencia habitual o permanente de una persona.

Igual connotación le van a dar al término, desde un punto de vista ontológico, Martin Heidegger (1975)- quien relacionó hábito con habitar: "morada del ser o estilo humano de habitar"-, y Vidal Marciano (1999) y Livio Melina (1996), quienes opinan lo mismo. El ethos es inicialmente la forma como la persona, en su "manera habitual de obrar", coincide con su “modo de vivir" (Gallego, 1999).

El segundo momento es la comprensión del término en la época poshomérica, cuando es entendido como costumbre o hábito, es decir ethos-ética se entiende como el "modo de comportarse, costumbre" (Sgreccia, 1999), sentido que también defiende el español José Ferrater Mora (1964), quien sostiene que la ética se ha definido con frecuencia como la doctrina de las costumbres.
Por su parte, el diccionario del griego bíblico también define el vocablo ethos como "usanza, práctica habitual, costumbres ancestrales, prescripción cultual con la ley" (Hubner, 1996); pero el ethos como vemos en su segunda comprensión, no se relaciona solo con costumbres sino también con hábitos (Melina, 1996).

El tercer momento se sitúa en la época aristotélica, cuando ethos, según Paulina Rivero, se relaciona con carácter ético y moral: De hecho, podemos decir que el carácter moral se adquiere, sin darse cuenta a veces, por medio de las costumbres, y el carácter ético se conquista con muchos esfuerzos, por medio de las costumbres.

Relacionar la ética con el "carácter o disposición, o manera de ser" lo afirma el Ministerio de Educación de Colombia (1998); y es que el carácter es, en ultimas, el estilo de vida que la persona le da a su existencia generado por actos particulares y concretos. Por eso el carácter, dirá Sennett, "se centra en particular en el aspecto duradero, «a largo plazo», de nuestra experiencia emocional" (2011). El estilo de vida, la manera de ser o el carácter "se adquiere con los hábitos los cuales" son "el resultado de la repetición de los actos" (Peláez, 1994).

Llegados a esta parte final del origen del término, observo, por un lado, que hay relación en los tres momentos de la interpretación del vocablo ethos, siendo el primero la base; y por otro, que el termino ethos nos remite a darle fuerza a la ética como la vida del carácter en una persona, y nos recuerda la famosa sentencia de Heráclito Ethos Antropos Daimon: “el carácter 
de un hombre es su destino". Es decir del carácter (ethos) como se habita, se mueve por medio de costumbres y hábitos se forja el destino de la persona, destino que se prepara en cada hoy y se profetiza frente al futuro (Jaspers, 1969).

\section{Ethos, ética: interioridad-exterioridad}

"Educar la mente sin educar el corazón, no es educar en absoluto" (Aristóteles)

Relacionar el ethos con la interioridad de cada persona es valorar la antropología como movimiento reflexivo hacia adentro de sí, es hablar del "hombre interior" con sus vivencias y deseos, aspecto que fue comentado por Juan Pablo II (1995) bajo el influjo de Max Seller y la tradición bíblica para referirse a una experiencia profundamente íntima que vive la persona en relación con recrear permanentemente la interioridad a imagen del ethos de la primera creación, es decir, permanecer en los valores y principios de la razón natural y de la alianza con Dios.

En griego difícilmente se encuentra la voz ethos, la cual se equipara a la palabra corazón, y por eso la narraciones bíblicas se centran en el cambio de corazón del pueblo, ajustar el corazón a la alianza; cambio que es tarea humana y divina, y compleja, pues deshabituar el corazón no es fácil: "Porque de lo que rebosa (abundancia) el corazón habla la boca" (Mateo 12:34 La Biblia de Jerusalem; "Engañoso es el corazón más que todas las cosas, y perverso; ¿quién lo conocerá? (Jeremías, 17:9 La Biblia de Jerusalem).

El ethos como modo de habitar nos remite a la interioridad humana (Giovanni Paolo II, 1995), al corazón habituado, a la forma como un sujeto o colectivo mora en su ser, o la manera como habita en lo más óntico por medio de costumbres y estilos de vida instaurados por hábitos que moldean y forman el carácter. Bien afirma el teólogo Ancille: "Raras veces quiere reflejar el concepto de costumbre de un pueblo; significa más bien el conjunto de disposiciones espirituales y emotivas de un hombre" (1984).

En la interioridad de cada persona, entonces, habita un mundo de valores que ella va jerarquizando y estructurando para hacerlo habitual; y por esta vía el ethos sujeto a desarrollo se construye con los valores morales que hacen vivir a la persona en el bien moral.

Cuando se ordena el habitar sobre un fundamento de valores sólidos, la existencia toma más sentido.

La vida de cada persona es movimiento de interioridad habituada, pero es además interioridad exteriorizada que repercute en su vida social, en las actividades, es decir, en las relaciones de una persona con sus semejantes, con la economía, la medicina, la política, el tiempo libre, el trabajo, y el planeta, "nuestra casa común" (Francisco, 2015); por lo tanto, si el ethos ordenado en valores no toca la vida, las decisiones de la persona o de un grupo humano, seguiremos viendo que "La política sin ética genera corrupción y opresión, que la economía sin ética genera injusticia y desarrollo para unas minorías privilegiadas, que la investigación sin ética genera graves amenazas frente a la dignidad de la persona" (Peláez, 1994) y el futuro del ecosistema. 
He aquí la importancia de saber educar para cuidar primero " el hombre interior", la manera como se habita en la 'casa' de cada persona, pues si no cambia la 'casa' (guarida) así como 'la interioridad moral acostumbrada a ciertos hábitos', difícilmente cambiarán las estructuras de la gran 'casa civil'.

Por ejemplo, para adecuar la convivencia ciudadana a la ética de los siete aprendizajes básicos para la convivencia civil (Toro, 1992): aprender a no agredir al otro, aprender a comunicarse, aprender a interactuar, aprender a decidir en grupo, aprender a cuidarse, aprender a cuidar el entorno, aprender a valorar el saber cultural, primero hay que formar y moldear el habitar de cada ciudadano, esto es, que cada ciudadano haga una opción fundamental en su ethos en la zona moral de las decisiones éticas.

Bien diría sobre este aspecto Battista Montini: "Las mejores estructuras, los sistemas más idealizados, se convierten pronto en inhumanos si las inclinaciones inhumanas del hombre no son saneadas, si no hay una conversión de corazón y de mente por parte de quienes viven en esas estructuras o las rigen" (Pablo VI, 1975).

\section{Ethos, ética: habitar con otros}

"La fuerza moral no ha crecido junto al desarrollo de la ciencia, sino que al contrario ha disminuido"(Josepth Ratzinger).

El ethos es una construcción personal y social que se edifica y se fundamenta. Para los griegos de la época aristotélica se fundaba en la vida virtuosa, y la vida ética era un proyecto político, es decir preocupación por el cuidado de sí, habituarse a vivir la virtud para vivir en la polis y así cuidar la ciudad (Men, 1998). Con el tiempo, el ideal de la polis griega da un giro para centrarse hoy en las libertades individuales y la "vida ética es un proyecto individual, basado en la justicia, y en la autonomía del sujeto que ha logrado la mayoría de edad"(García, 2008).

Sin embargo, la construcción del ethos como forma de vivir tanto individual como social, es dinámica, sujeta a variables, y pueden existir diferentes formas de morar según las personas y sociedades y situaciones; afirmación que no puede interpretarse como patrocinar la trampa del relativismo o subjetivismo ético que tiende a propagarse en ambientes, pues la experiencia del bien, de la verdad, de la justicia, de los valores morales, no se puede minimizar frente a la difusión de acoger hoy el sano pluralismo, el cual nos advierte que en el ethos de la aldea global (McLuhan, Powers, 1995), los ciudadanos deben aprender a vivir en una sociedad que acoge extraños morales (Engelhart, 1993), con un politeísmo ético (D'Agostino, 1998), axiológico (Vidal, 1999) o valorativo, y en donde se propone que la verdad se descubre por consenso y acuerdos. Bien afirma Adela Cortina: "El consenso no es solo el lugar de la verdad, sino también el lugar de lo moralmente correcto" (1995).

Se vienen entonces proponiendo entre otras alternativas para fundamentar el ethos de la convivencia moderna en la polis, la vivencia de los derechos humanos o la ética de mínimos (Cortina, 1986), o de máximos (García, 2014), o de principios como el de la responsabilidad: "Obra de tal manera que no pongas en peligro las condiciones de la continuidad indefinida de la humanidad en la Tierra" (Jonas, 1995), el aporte 
de la bioética (Tettamanzi, 2000), la difusión de la justicia social (Rawls, 1997), o la propuesta de la conversión ecológica del papa Francisco (2015), o las grandes contribuciones de Delors (1996) y Morin (1999). Sin embargo, con toda esta riqueza de propuestas para saber habitar con otros, estoy convencido de que siempre hay un ethos común que la razón y la conciencia comprenden, y trasciende a todas las personas, a todos los pueblos, y es el de habituarse a convivir en principios, valores, en un orden moral, respetando los derechos humanos, que se fundamentan en la sacra dignidad de cada persona (Pontificio Consiglio per la familia, 1999) y en la ley natural presente en todos las culturas: "Haz bien y evita el mal" (Santo Tomás).

El aporte de la toma de conciencia de un estado social de derecho, la contribución que hacen las religiones, la educación ética desde la filosofía y la llamada hoy "educación ciudadana" son estrategias educativas en favor de la construcción de un ethos común donde es posible coexistir pacíficamente con los próximos cercanos y próximos lejanos (Gunthor,1998).

\section{Ethos, ética: reflexionar con otros el arte de vivir \\ "La fuerza moral no ha crecido junto al desarrollo de la ciencia, sino que al contrario ha disminuido"(Joseph Ratzinger).}

El ethos es una construcción personal y social que se edifica y se fundamenta. Para los griegos de la época aristotélica se fundaba en la vida virtuosa, y la vida ética era un proyecto político, es decir preocupación por el cuidado de sí, habituarse a vivir la virtud para vivir en la polis y así cuidar la ciudad (Men, 1998). Con el tiempo, el ideal de la polis griega da un giro para centrarse hoy en las libertades individuales y la "vida ética es un proyecto individual, basado en la justicia, y en la autonomía del sujeto que ha logrado la mayoría de edad"'(García, 2008).

Sin embargo, la construcción del ethos como forma de vivir tanto individual como social, es dinámica, sujeta a variables, y pueden existir diferentes formas de morar según las personas y sociedades y situaciones; afirmación que no puede interpretarse como patrocinar la trampa del relativismo o subjetivismo ético que tiende a propagarse en ambientes, pues la experiencia del bien, de la verdad, de la justicia, de los valores morales, no se puede minimizar frente a la difusión de acoger hoy el sano pluralismo, el cual nos advierte que en el ethos de la aldea global (McLuhan, Powers, 1995), los ciudadanos deben aprender a vivir en una sociedad que acoge extraños morales (Engelhart, 1993), con un politeísmo ético (D'Agostino, 1998), axiológico (Vidal, 1999) o valorativo, y en donde se propone que la verdad se descubre por consenso y acuerdos. Bien afirma Adela Cortina: "El consenso no es solo el lugar de la verdad, sino también el lugar de lo moralmente correcto" (1995).

Se vienen entonces proponiendo entre otras alternativas para fundamentar el ethos de la convivencia moderna en la polis, la vivencia de los derechos humanos o la ética de mínimos (Cortina, 1986), o de máximos (García, 2014), o de principios como el de la responsabilidad: "Obra de tal manera que no pongas en peligro las condiciones de la continuidad indefinida de la 
humanidad en la Tierra" (Jonas, 1995), el aporte de la bioética (Tettamanzi, 2000), la difusión de la justicia social (Rawls, 1997), o la propuesta de la conversión ecológica del papa Francisco (2015), o las grandes contribuciones de Delors (1996) y Morin (1999). Sin embargo, con toda esta riqueza de propuestas para saber habitar con otros, estoy convencido de que siempre hay un ethos común que la razón y la conciencia comprenden, y trasciende a todas las personas, a todos los pueblos, y es el de habituarse a convivir en principios, valores, en un orden moral, respetando los derechos humanos, que se fundamentan en la sacra dignidad de cada persona (Pontificio Consiglio per la familia, 1999) y en la ley natural presente en todos las culturas: "Haz bien y evita el mal" (Santo Tomás).

El aporte de la toma de conciencia de un estado social de derecho, la contribución que hacen las religiones, la educación ética desde la filosofía y la llamada hoy "educación ciudadana" son estrategias educativas en favor de la construcción de un ethos común donde es posible coexistir pacíficamente con los próximos cercanos y próximos lejanos (Gunthor,1998).

\section{Ethos, ética: reflexionar con otros el arte de vivir}

"Se puede de muchos modos, pero hay modos que no dejan vivir" (Fernando Savater)

La ética, fuera de expresar una connotación ontológica-antropológica en la persona, es una reflexión centrada en la acción humana, entendida como aquellas acciones que perfeccionan a la persona en el bien moral y no en las acciones que la persona hace por lo menos cuando aplica una técnica o un arte (De Finance, 1989). Así, la ética está relacionada con el arte de vivir, pero vivir la vida virtuosa, amar la vida buena, no cualquier otra vida. Edgar Morín dirá: "La reforma de la vida es, en primer lugar, la conquista de un arte de vivir" (2011).

En este contexto Fernando Savater ve la ética como el 'arte de vivir', del buen vivir precisando que "Se puede vivir de muchos modos, pero hay modos que no dejan vivir" (1991), lo cual quiere decir que hay saberes imprescindibles, como por ejemplo, saber que ciertas cosas nos convienen y otras no. No nos convienen tampoco ciertos alimentos, ni ciertos comportamientos si queremos seguir viviendo (Savater, 1991).

Por lo tanto, no basta ordenar la vida, el ethos de cualquier forma, esto es, "no basta cualquier estilo de vida, ni cualquier forma de actuar" (Vico, 1999); el arte de vivir consiste en que la persona ordene y oriente su habitar de modo que pueda vivir las realidades de su existencia personal (vida privada) y su existencia social (vida pública) buscando el bien propio y el bien común.

El arte de vivir es el estilo de vida que debe ser dirigido hacia "aquello que le conviene a la persona, pues en un estilo de vida, la persona se puede perder, puede ganar, humanizarse, deshumanizarse" (Vico, 1999). Con la ética la persona ordena su vida de forma digna; por eso, hay que saber formular nuestra el orden de vida buena (Chalmeta, 1996).

De lo anterior surgen discusiones éticas que parecieran no tener fin en cuanto legitimar o 
deslegitimar costumbres o modos de pensar y vivir, pues pareciera ser algo que resulta complejo, pero no podemos desconocer que por la filosofía el ethos adquiere connotaciones de juicio de valor en las personas y en la sociedad, como por ejemplo, al utilizarse como adjetivo para saber "si una acción, una cualidad, una virtud o un modo de ser son o no éticos" (Ferrater, 1964).

En este punto es preciso comentar, desde lo filosófico, que durante décadas la 'ética' era una voz minoritaria en contraposición de la voz 'moral' y ambas palabras se usaban en un sentido unívoco; pero desde hace varias décadas la palabra 'ética' fue tomando un matiz secular, laical, filosófico de independencia y autonomía, en contraposición de la influencia religiosa en la cultura de la ética revelada (o teología moral), llegándose a que hoy el vocablo ética tiene más relevancia y acogida en las culturas donde se desea ordenar y ajustar la convivencia, no por medio de la ética revelada cristiana (o moral cristiana), sino por medio de las éticas civiles, esto es, aquellas que se fundamentan en las democracias y los derechos humanos.

Por último, la palabra ética y su evolución como ciencia reflexiva se han relacionado con los sistemas éticos que han nacido en el caminar de la historia de la humanidad y de la filosofía: éticas de la razón, éticas del deber, éticas altruistas, éticas religiosas, éticas de la libertad, éticas cósmicas, éticas de la felicidad (De Finance, 1989); ética y bioética (García, 2008), etc.

\section{Ethos, ética y el arrebato}

"Abrir mi casa es permitir que entre la divinidad. El filósofo le dice a sus discípulos cuando lo miran desde la puerta de su casa: entrad, los dioses también viven aquí. Entrar en mi casa, es entrar en mi existencia, en mi templo y ved en ella lo divino. Quien entra a mi casa le participo mi horizonte, el futuro" (Stanislaw Grigyiel).

El encuentro entre personas es un intercambio de un mundo de valores habituales que revela cómo habita cada uno, cómo vive en su casa, haciendo llamativa muchas veces en dicho encuentro, la pregunta que le hicieron los discípulos al maestro: “¿Maestro, dónde vives?, a lo que él respondió: ¡Venid y os enseñare! Y los discípulos se quedaron todo el día con el maestro" (Juan 1:39 La Biblia de Jerusalem).

Hay formas de vivir o habitar que apetece entrar, conocer, contemplar y otras de las que es preferible distanciarse por su mediocridad (Ingenieros, 2000), o el peligro que ofrecen por "sus ídolos" (García, 2015); otras son solo 'fachadas'. Por eso, un cometido de la educación es dejar en los "formandos" la responsabilidad social con lo personal, civil y profesional (García, 2015) para suscitar ante los demás el "arrebato", es decir, la provocación y admiración por la manera como se vive en su casa-ethos. Pienso en el rol de los padres, de los cónyuges, del educador, del jefe, del gobernante.

Habitar solo de fachada es apariencia, no es autenticidad, y esta vivencia cuando se conoce no provoca el arrebato, sino el desencanto. "Ser una simple apariencia es muy triste sobre todo cuando nos encontrarnos de cara a la verdad de nuestra vida, que tarde o temprano nos pasa la factura" (García, 2014). 
En la educación, suscitar en el discípulo el "arrebato" hacia una forma mejor de habitar, solo es posible si primero el maestro ha sido arrebatado para habitar su casa con lo bello (pulcrum), lo bueno (bonum) y lo verdadero (verum) (Corchuelo, 2014).

Los valores religiosos ayudaran bastante a este componente, así como aquellos que vienen de la ética; pero destaco que ya en Heráclito el ethos incluye el habitar en la divinidad, pues el habitar humano también es espacio para lo divino y para dejarse arrebatar por lo Absoluto.

El polaco Grygiel traduce así la expresión de Heráclito: "Casa para el hombre es la divinidad"ethos antropo daimon (2002); y en la teología cristiana el habitar de la divinidad en lo humano se condensa en la expresión del judío Pablo de Tarso: "Es Cristo quien vive en mí" (Gálatas 2: 20 La Biblia de Jerusalem)

\section{Reflexión Final}

Hay una gran demanda de estudiantes que ingresan al mundo de lo superior, estamos en la sociedad del conocimiento, la gran época de la sociedad de la inclusión. En pregrado los jóvenes (habitan cinco años), hacen especializaciones (un año), maestrías (dos años) y doctorados (cuatro años), y ¿cómo sale edificado su carácter, su corazón, su hombre interior en la forma de habitar?

La palabra 'habitar' nos ha remitido a la ética (ethos), que desde un punto de vista etimológico expresa la costumbre, la permanencia moral, (la manera como la persona mora, habita); el estilo usual de vivir, la interioridad humana o el corazón humano habituado a un centro de valor. Hablar del habitar en su dimensión de interioridad es tocar lo profundo de lo humano: lo que le gusta oír, seguir, frecuentar; cómo vive, piensa, el sentido que tiene del bien moral y de la verdad.

El termino ethos refleja entonces una carga antropológica y ética, pues es "una realidad interior y personal" (Ancille.1984), la forma como una persona o grupo se acostumbra a vivir por medio de sus hábitos para templar el carácter, pues los hábitos, según Paulina Rivero, se deben "elegir correctamente, en ellos radica esa forma de ser adquirida, esa segunda naturaleza que Aristóteles llama carácter".

Hablar de ética es provocar la pregunta que hace filosofía sobre los estilos de vida, y la universidad contribuye eficazmente cuando en el habitar del estudiante o del docente se logra generar el "apostar a otro estilo de vida" (Francisco, 2015); por eso, presentar formas deseables en el arte de vivir es un cometido y un reto, para provocar, además, en el educando, la tarea ética de salvar su morada, su alma, porque su carácter (ethos) es su destino.

Recuerdo aquí las estrategias dadas por Torralba para cultivar en la universidad la inteligencia espiritual y con ella la vida del ethos: introspección, contemplación, la música, el diálogo y el salir hacia el otro; la educación liberal de la que habló Newman (Gutiérrez, 2013), y desde mi experiencia la propuesta de la vida virtuosa (García, 2014), y aprender a formar el hombre interior mediante el gobierno de sus deseos y pensamientos - es decir con la vigilancia 
del corazón (Spidlík, 1999)- e indignándose cuando el habitar se convierta en guarida de mediocridad, es decir acostumbrarse al mundo de lo inferior.

Por tanto, la educación debe siempre favorecer espacios en la persona, en el alumno, en el profesional para la pregunta y la reflexión: ¿qué habita en 'mi casa'?, y así puedan darse cuenta de la magnitud de la respuesta: ¡la verdad o el ídolo! (García, 2015). He aquí la importancia de tener grandes maestros que teniendo una 'casa' bien ordenada-habituada, provocan el arrebato del discipulado por la verdad, mientras el discípulo aprende junto a él. Una existencia centrada en los trascendentales, cuando se encuentra con los otros hace provocar la pregunta: ¿"Maestro, dónde vives? Y el maestro puede responder: "Ven y verás".

Formar desde la universidad es educar a saber vivir en lo privado y lo público, es permitir que el otro conozca mi casa, mi existencia, y vea en ella el mundo de mis valores morales y culturales, los principios, la vida virtuosa, y en términos de Grygiel, la divinidad; pero si no está la verdad, lo divino en mi casa, 'estará', en términos teológicos, la mentira: Beelzebul (Mateo 12:24 La Biblia de Jerusalem), y entonces se hará necesario usar la 'mascara' (prosopón) para vivir en apariencia con otros y consigo mismo.

La formación superior es vital en la construcción de un ethos ciudadano, y la universidad debe formar, en su 'vientre' o en su morada, ciudadanos capaces de construir el anhelo de una sociedad basada en principios de justicia social (Osorio, 2010), ciudadanos que logran indignarse (Hessel, 2010) por una vida que los tienta con la mediocridad y son capaces de asumir costumbres y hábitos de liderazgo para combatir el ethos del subdesarrollo con la disciplina; ciudadanos que salen de la universidad con un alto concepto de la dignidad humana; ciudadanos que son capaces de vivir y defender los valores de la autenticidad, la libertad, la solidaridad, la responsabilidad, el respeto por la diferencia. En definitiva, ciudadanos apasionados por cuidar su morada, su carácter, para no dejarlo "corroer" en lo transitorio y acelerado de la vida.

Hay que difundir la competencia para la vida de la educación del carácter mediante el gobierno de la casa, del corazón, del hombre interior, pues si no se educa la forma de habitar, el hombre de los deseos, de los buenos y malos; se prepara cada vez una civilización presa de los deseos sin gobierno y quien pierde es el hombre público con su declive (Sennett, 2011).

Antropológicamente, la persona está destinada a lo superior, lo magno, por lo tanto hay que crear hábitos para habitar en la verdad o si no la persona, metafóricamente, está muerta, porque muere lentamente quien se trasforma en esclavo del mal hábito, repitiendo todos los días los mismos trayectos; muere lentamente quien no cambia de ruta.

\section{Referencias}

Ancille, E. (1984). Nuevo Diccionario de Espiritualidad, Voz Moral, T.II, Herder: Barcelona

Chalmeta, G. (1996). Ética Especial. Pamplona, España: Eunsa 
Corchuelo, F. (2014). Luz y sombras de la vida religiosa y espiritual. Bogotá, Colombia: Frailes Dominicos

Cortina, A. (1986). Ética Minima, Madrid, España: Teonos Cortina, A. (1995). Razón comunicativa y responsabilidad solidaria, Sígueme: Salamanca

D'Agostino, F. (1998). Bioética, Torino: Italia

De Finance, J. (1989). Ética Generale, Cassano Murge: Bari, 1989

Delors, J. (1996). La educación encierra un tesoro, Unesco: Paris

Engelhart, H. (1993). Ensayo sobre 'Bioetica: laica e religiosa. Pensiero: Milano

Ferrater, M., J. (1964). Diccionario de Filosofia, Tomo I, voz Ética, Montecasino: Buenos Aires

Gallego, C. (1999). Ética y Valores, Postergraph: Pereira,

García, S. (2008). Formación profesional en Bioética. Bogotá: San Pablo

García, S. (2014). La práctica de virtud cuida la vida, en Diferentes puntos de vista sobre el desarrollo y la sostenibilidad, 266-287. ISBN: 978-958-12-0352-9 (PDF); 978-958-12-0353-6 (en línea); Fundación Universidad de la Sabana: Bogotá.

García. S. (2014). Repensar la formación humana en la modernidad. Revista de investigaciones UNAD. Volumen 13. Número 2.
Diciembre 2014. Pp.149-168. BogotáColombia

García, S. (2015). Aporte del cristianismo para educar en la responsabilidad social. Reflexiones antropológicas y éticas. In Crescendo. Educación. 2015; 2(1): 49-62. Perú

García, S (2015). El peligro de los ídolos. San Pablo: Bogotá

Grygiel, S. (2002). Extra Comunionem Personarum, Universidad Pontificia Lateranense: Roma.

Gunthor, A. (1998). Chiamata e risposta, TIII, Paolini, Milano 1998 pp.37-39

Gutiérrez, L. C. (2013). John Henry Newman y la idea de la universidad, ITAM, Estudios 106, vol.XI, otoño

Heidegger, M. (1975). Lettera sullúmanesimo, Torino, 1975

Hessel, S. (2010). Indignáos. Montpellier: indigene editions

Hubner, H. (1996). Diccionario Exegético del Nuevo Testamento, V.I, Sígueme: Salamanca

Ingenieros, J. (2000). El hombre mediocre, Aleph.com, www.educ.ar

Jaspers, K. (1969), Entre el destino y la voluntad, Guadarrama: Madrid.

Jonas, H. (1995). El principio de responsabilidad. Barcelona, España: Herder 
McLuhan, M., Powers, B.R. (1995). La aldea global. Transformaciones en la vida y los medios de comunicación mundiales en el siglo XXI, Gedisa: Barcelona

Melina, L. (1996). Moral: Entre Crisis y Renovación, Internacionales Universitarias: Barcelona,

Morin, E. (1999). Los siete saberes necesarios para la educación del futuro, Unesco: Paris

Osorio, S. (2010). John Rawls: una teoría de justicia social. Su pretensión de validez para una so ciedad como la nuestra. rev.relac.int.estrateg.segur. vol. 5 no. 1 - enero junio:137-160: Bogotá

Pablo VI (1975). Exhortación Apostólica, La Evangelización del mundo contemporáneo, Roma.

Papa Francisco (2015). Laudato si. Sobre el cuidado de la casa común. Roma

Peláez, H. (1994). ¿Un lugar para la ética en la Universidad?, en Simposio Permanente sobre la Universidad, por Alfonso Borrero, p.3.

Pontificio Consiglio per la familia. (1999). Diritti Dell'Uomo: Famiglia e Política, Editrice Vaticana: Roma,
Rawls, J. (1997). Teoría de la justicia, Traducción de María Dolores González, Fondo de Cultura Económica: México

Savater, F. (1991). Ética para Amador, Presencia: Bogotá

Sennett, R. (2011). El declive del hombre público, Barcelona, España: Anagrama

Sennett, R. (2011). La corrosión del carácter. Las consecuencias personales del trabajo en el nuevo capitalismo, Barcelona, España: Anagrama.

Sgreccia, Elio. (1999). Bioética Manuale per $i$ Diplomi Universitari della Sanitá, Vita e Pensiero: Milano

Tettamanzi, D. (2000). Nuova Bioetiaca Cristiana, Piemme, Casale Monferrato: Milano

Toro, J. (1992). Siete aprendizajes básicos para la educación en la convivencia social, Fundación Social: Bogotá.

Torralba, F. (2010). Inteligencia Espiritual, Plataforma: Barcelona

Vico, J. (1999). Éticas Teológicas ayer y hoy, Paulinas: Madrid

Vidal M. (1999). 10 palabras clave en Moral del futuro, Verbo Divino: Navarra 